\title{
Mechanical Properties of Low Density Polyethylene / Citrus Aurantium Shell Composite
}

\author{
Hamed A. Hamde \\ Department of Materials Science / Polymer Research Center \\ University of Basarh
}

Received

19 / 05 / 2010
Accepted
$01 / 06 / 2011$

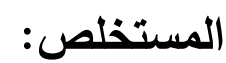

تم في هذا البحث تقييم الخواص الميكانيكية للخليط البوليمري (بوليمر الاثيلين واطئ

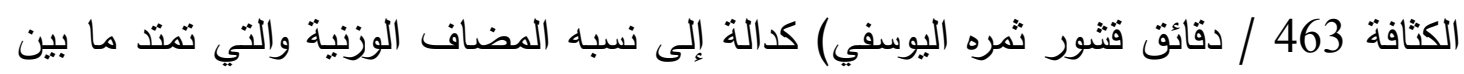

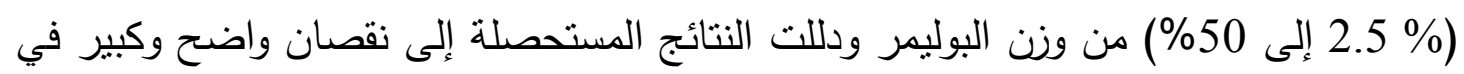

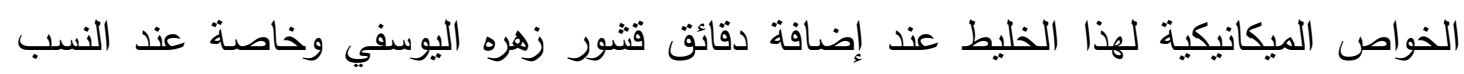
العالية حيث اعتمد مقدار التغير المرن الحاصل في النماذج البوليمرية المحملة بقثور ثمره

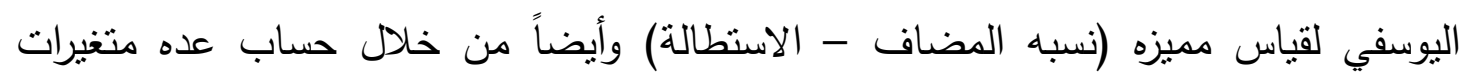

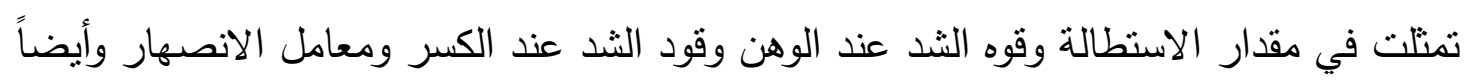

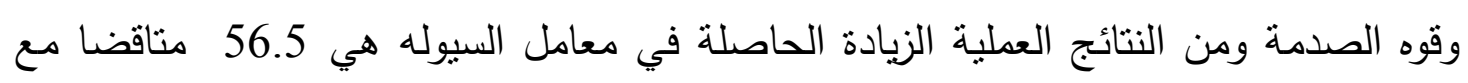

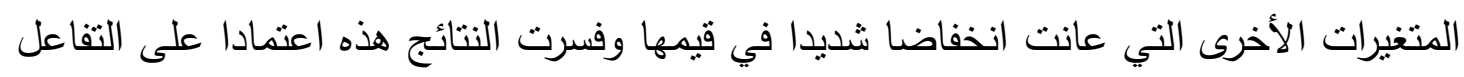

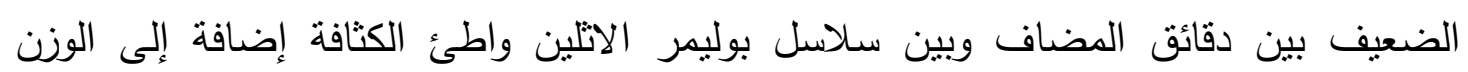
الجزيئي القليل المصحوب للسلاسل البوليمرية القصيرة مما اثر سلبا على قابليه الثد والاسنطالة الثالئ

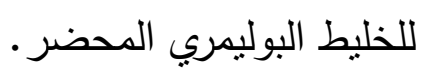

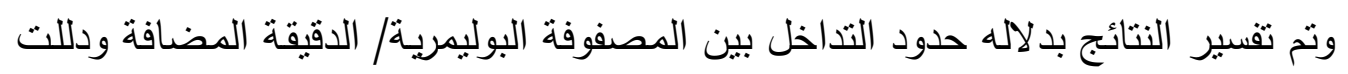

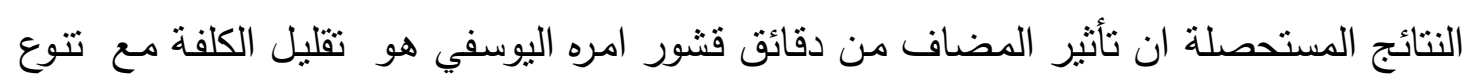

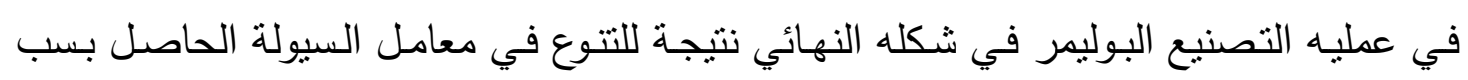

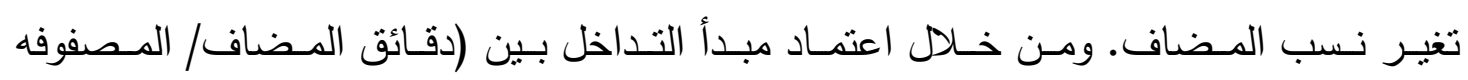

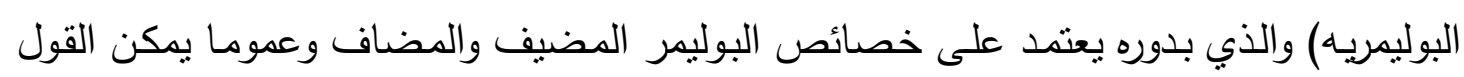

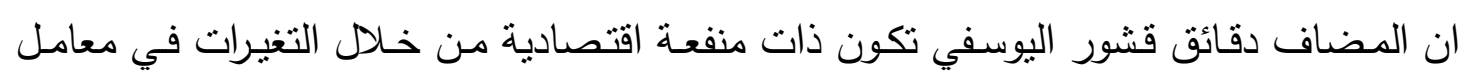
الانصهار واللزوجة ونقصان كميه البولي الاثيلين واطئ الكثافة الداخلة في الخليط البوليمري. Abstract: 
Mechanical properties of (LDPE-463)/Citrus Aurantium shell composite are assessed with respect to the effect of Citrus aurantium shell content varying from $2.5 \%$ to $50 \%$. An obvious decrease in the mechanical parameters is recorded after adding Citrus aurantium shell of a high weight ratio. The mechanical properties of loaded film have been evaluated through several parameters concerning the elastic deformation based on measuring the load - elongation characteristics. The melt index is found to be increased up to 56.5 with increasing the filler concentration up to $50 \%$, while the incorporation of the filler has adversely affected mechanical properties by reducing the tensile at yield and break, impact and elongation. This reduction is due to two reasons poor interaction between filler particles and LDPE chains and low molecular weight of the short molecular chains of the composite thus resulting in a lower tensile strength and elongation at yield and break and may be related to particles/matrix interface which depends on the properties of both the filler and the host polymer. Finally the filler contributes to reducing the cost due to the change made in melt index, viscosity and the reducing of LDPE in the composite matrix.

\section{Introduction :}

A number of additives have been added to the polymer to serve different industrial requirements. Among these are lubricants, antioxidant, ant blocking agent, slip agent, antistatic, stabilizer, color compounds, foaming agent and fillers (1-2). The term filler is very broad and encompasses a very wide range of materials including variety of solid particulate materials (inorganic, organic) that may be irregular, acicular, fibrous or plate-like in shape and which are used in reasonably large volume loadings in plastics(3). Traditionally, fillers are considered as additives, which, due to their unfavorable geometrical features, surface area or surface chemical composition, could only moderately increase the modulus of the polymer, while strength (tensile, flexural) re-mained unchanged or even decreased. Their major contribution is in lowering the cost of materials by replacing the more expensive polymer; other possible economic advantages are faster molding cycles as a result of increased thermal conductivity and fewer rejected parts due to warpage. Depending on the type of filler, other polymer properties could be affected; for example, melt viscosity could be significantly increased through the incorporation of fibrous materials. On the other hand, mold shrinkage and thermal expansion would be reduced, a common effect of most inorganic fillers. Almost $85 \%$ of polymers produced worldwide are thermoplastics (4-5) where polyethylene is one of these polymers and the basic characteristics of low density polyethylene behind its potential mechanical properties are candidate it's utilization in different 
applications compared to others. The basic characteristics of mechanical properties of solid are usually determined by testing results dependencies, such as stress-strain diagram where the tensile stress-strain is most widely used(6). Owing to the viscoelastic nature of polymers, the test is only a rough guide to how a polymer will behave in a finished product $(4,6)$. The tensile test is widely used for measuring stiffness, strength, dimension stability and ductility of the polymer. Finally Global demand for fillers/reinforcing fillers, including calcium carbonate, aluminum trihydrate, talc, kaolin, mica, wollastonite, glass fiber, aramid fiber, carbon fiber, and carbon black for the plastics industry is estimated to be about 15 million tons(7). In order to convert low-value citrus aurantium resources into high-value product, citrus aurantium shell is combined with thermoplastic resin resulting in particles of citrus aurantium shell plastic composite.

The present paper summarizes the obtained results of mechanical properties of (1DPE- citrus aurantium shell) for different doping weight percentage $(2,5 \%-50 \%)$.Parameters such as elongation, tensile at yield, tensile at break, impact and melt index are taken in to contribution.

\section{Experimental Procedure:}

Additive-free LDPE (SCILEN 22004) grade is supplied from the state company for petrochemical industry (SCPI) of (MI=0.39 $\mathrm{gm} / 10 \mathrm{~min}$.) and (density $=0.922 \mathrm{gm} / \mathrm{cc}$ ). The citrus aurantium shell is obtained from local market. The average citrus aurantium shell particle size used in this work is $(<125) \mu \mathrm{m}$. Six concentrations of sawdust particles $2.5,5,10,15,25,30$ and $50 \mathrm{wt} \%$ are used in the LDPE compounds. Citrus aurantium shell as a fine powder is mixed with LDPE using Rheomix mixer 600 instrument attached to Haake Rehochard meter with following conditions; mixing time $15 \mathrm{~min}$; mixing temperature $160^{\circ} \mathrm{C}$; mixing velocity $32 \mathrm{RPM}$. After that the final mold product is introduced in a laboratory compress under 5 ton at $175^{\circ} \mathrm{C}$ for 3 minutes in a square frame where the pressure rises gradually up to 15 ton for a (6) minutes and after this period the sample sheet is cooled up to reach room temperature. This sheet of final product is used to prepare Samples dumbbell in shape for measuring the mechanical properties and melt index by using Instron instrument model 1193 with following conditions; chart speed (10) $\mathrm{mm} / \mathrm{min}$, crosshead speed $50 \mathrm{~mm} / \mathrm{min}$. The test specimen is positioned vertically in the grips of device then the grips are tightened evenly and firmly to prevent any slippage. The relationship between elongation and load is obtained directly from the instrument. All measurements are made according to [ASTM D638 1977] (8).

To measure the tensile strength of a polymer sample, we usually stretch it using Instron machine. This machine simply clamps each end of the sample and stretches the sample. It measures the amount of force $(F)$ 
it is exerting. When we know the force being exerted on the sample, we then divide that number by the cross-sectional area $(A)$ of our sample. The answer is the stress that our sample is experiencing by increasing the amount of force, and stress naturally, on the sample until it breaks. The stress needed to break the sample is the tensile strength of the material.

Elongation is a type of deformation where the sample deforms by stretching, and becomes longer. We call this elongation. Usually we talk about percent elongation, which is just the length the polymer sample is after it is stretched $(L)$, divided by the original length of the sample $\left(L_{0}\right)$, and then multiplied by 100 .

\section{$\frac{L}{L_{0}} \times 100=\%$ elongation}

To measure tensile modulus, we do the same thing as we did to measure strength and ultimate elongation. This time we measure the stress we're exerting on the material, just like we did when we measured tensile strength. We slowly increase the amount of stress, and then we measure the elongation the sample undergoes at each stress level. We keep doing this until the sample breaks. Then we make a plot of stress versus elongation.

This plot is called a stress-strain curve. (Strain is any kind of deformation, including elongation. Elongation is the word we use if we're talking specifically about tensile strain.) The height of the curve when the sample breaks is the tensile strength, of course, and the tensile modulus is the slope of this plot. That plot of stress versus strain can give us another very valuable piece of information. Toughness is the measure of the area underneath the stress-strain curve. Toughness is really a measure of the energy a sample can absorb before it breaks.

Melt Flow Index is the output rate (flow) in grammes that occurs in 10 minutes through a standard die of $2.0955 \pm 0.0051 \mathrm{~mm}$ diameter and $8.000 \pm 0.025 \mathrm{~mm}$ in length when a fixed pressure is applied to the melt via a piston and a load of total mass of $2.16 \mathrm{~kg}$ at a temperature of $190^{\circ} \mathrm{C}$ (some polymers are measured at a higher temperature, some use different weights and some even different orifice sizes). In this research the melt flow index was measured according to ASTM D-1238 (10-11).

\section{Results and Discussion:}

Melt index as a function of citrus aurantium shell concentration is measured to determine the rheological properties and the viability of the composite. Figure (1) shows the values of melt index of the composite increase as the content of filler increased. The increment in melt flow index values indicates the viscosity of the composite decreased which is not similar to the most filled thermoplastic and in disagreement with that reported by researchers before(12). The increment maybe due to the citrus aurantium particle melting and losing their original shape to functioned as 
soft particulate fillers when processed with good dispersion of filler particles during melt compounding.

Experimental data of tensile at yield, tensile at break, elongation, impact are calculated. The effect that a filler will have on tensile strength depends on how much force it takes to pull it out of the polymer matrix where in our study the tensile strength is decreased. The obtained results of tensile strength at break and tensile at yield of (LDPE/citrus aurantium particle) composite are shown in figure (2) and figure(3). These results stating that the tensile strength at break decreased as the filler content increased. These results can be explained in terms of the small aspect ratio (the aspect ratio here is the ratio after compounding where a filler aspect ratio can be reduced by particle breakage during melt compounding) of our filler which deceases the tensile of break and yield because there is no more surface to grip the polymer.

Figure (4) shows the variation of Izod impact with filler concentration where a sharp decrease is obtained with filler ratio. The decrease in Impact may be explained in terms of the crack propagation through the polymer matrix which leads to the decrease impact strength where the little interaction between LDPE and added filler specially at a high ratio is responsible for non improvement of the Izod impact. The poor ability of material to tolerate load which consequently results in non improved distribution of stress and poor mechanical properties (13). The same behavior is obtained for the changes made to the Elongation of LDPE due to adding a different filler concentration as shown in figure (5). The Elongation of the composite is significantly less than that at a higher filler content. This result can be explained in to term of the interfacial properties of filler particles in LDPE at a lower Citrus aurantium shell content and by the distance between Citrus aurantium shell particles at a higher filler content respectively (14). In general, A polyethylene resin with small Melt flow index (MFI) values has a high molecular weight and long molecular chain thus the short molecular chain and high molecular weight do not help improving the interfacial adhesion between polyethylene macromolecules by polymer chain entanglement .Furthermore energy absorption to the impact load with respect to the LDPE with a short molecular chain and low molecular weight is not much sufficient due to high molecular weight and long molecular chain, thus resulting in non improvement of the elongation of LDPE/Citrus aurantium shell particles(15).

\section{Conclusion:}

Many changes in mechanical properties of the composite are due to the reinforcement of Citrus aurantium shell particles and poor interaction between filler particles and polymer chains specially at higher filler contents.

Melt flow index (MFI) significantly affect mechanical properties. The processing of doped samples is easier than that of pure samples. The tensile and impact strength decrease with an increase in the MFI value. 
The poor mechanical performance of the composite indicates the inherent difficulty of good adhesion between the Citrus aurantium shell particles and LDPE chains.

\section{References :}

1) Kalson, C. McQueen, D.H., and kubat, J.1996: Macromol. Symp, 108 247, Krevelen, D.W.V., and. Hoftyzer, P.J 1976: Properties of Polymers, N.Y.

2) Kuzel, R. and, krivka I.1994: Synthetic Metals 67, P.255, Narkis, M. Ram, A. and Flashner, F. 1978:, Engineering and Science 18, 649.

3) Functional Fillers for Plastics. Edited by M. Xanthos Copyright $(2005$ WILEY-VCH Verlag GmbH \& Co KgaA ISBN 3-527-31054-1.

4) Xanthos, M., Todd, D. B., "Plastics Processing", Kirk-Othmer Encyclopedia of Chemical Technology, 4th Ed., John Wiley \& Sons, New York, 1996, 19, pp 290-316.

5) Xanthos, M., "The Physical and Chemical Nature of Plastics Additives", Chapter 14 of Mixing and Compounding of Polymers Theory and Practice (Eds.: Manas-Zloczower, I., Tadmor, Z.), Carl Hanser Verlag, Munich, New York, 1994, pp 471-492.

6) Abdul Ghafor, W.A.S, Kalaf, M. N and Abdul Kader, A.F.2001: Proceeding for the 5th science conferences 33-24 October 2001, Science college, university of Mustanseria, Baghdad, Iraq.

7) Mahajan, S., Proc. Functional Fillers for Plastics 2003, Intertech Corp., Atlanta, GA, Oct.2003.

8) American Society for Testing and Materials, 1997, "Standard test method for tensile properties of plastics," ASTM standard ASTM D638-97, ASTM, Philadelphia, PA.

9) Raghupathi, N., "Long Fiber Thermoplastic Composites", Chapter 7 of Composite Materials Technology (Eds.: Mallick, P. K., Newman, S.), Hanser Publishers, Munich, 1990, pp 237-264.

10) Dorel Feldman, "Polymeric Building Materials", Chapter 1, p.3741. Elsever Applied Science, N.Y., 1989.

11) Jang, B. Z.; Advanced Polymer Composites: Principles and Applications, ASM International, Materials Park, OH, 1994.

12) Wan Aizan, Wan Abdul rahman, Roshafima Rasit Ali and Naterah zakaria, Proceedings of the 1st International Conference on Natural Resources Engineering \& Technology 2006, 24-25th July 2006; Putrajaya, Malaysia, 434-444.

13) Kramer, E.J., "Fudemental processes of craze growth and fracture", Adv. Poly. Sci., 91/92:1-68, 1990.

14) Bikiaris D. and C.Panayiotou, LDPEL/Starch blends compatibilities with PE-g-MA copolymers, J.Appl. Polyn. Sci. 70; 1503-1521,1998.

15) John $\mathrm{Z}$. Lu, Qinglin $\mathrm{Wu}$, Ioan I.Negulescu, Yan Chen, J.Appl.Polyn.Sci.Vol.102, 5607-5619, 2006. 

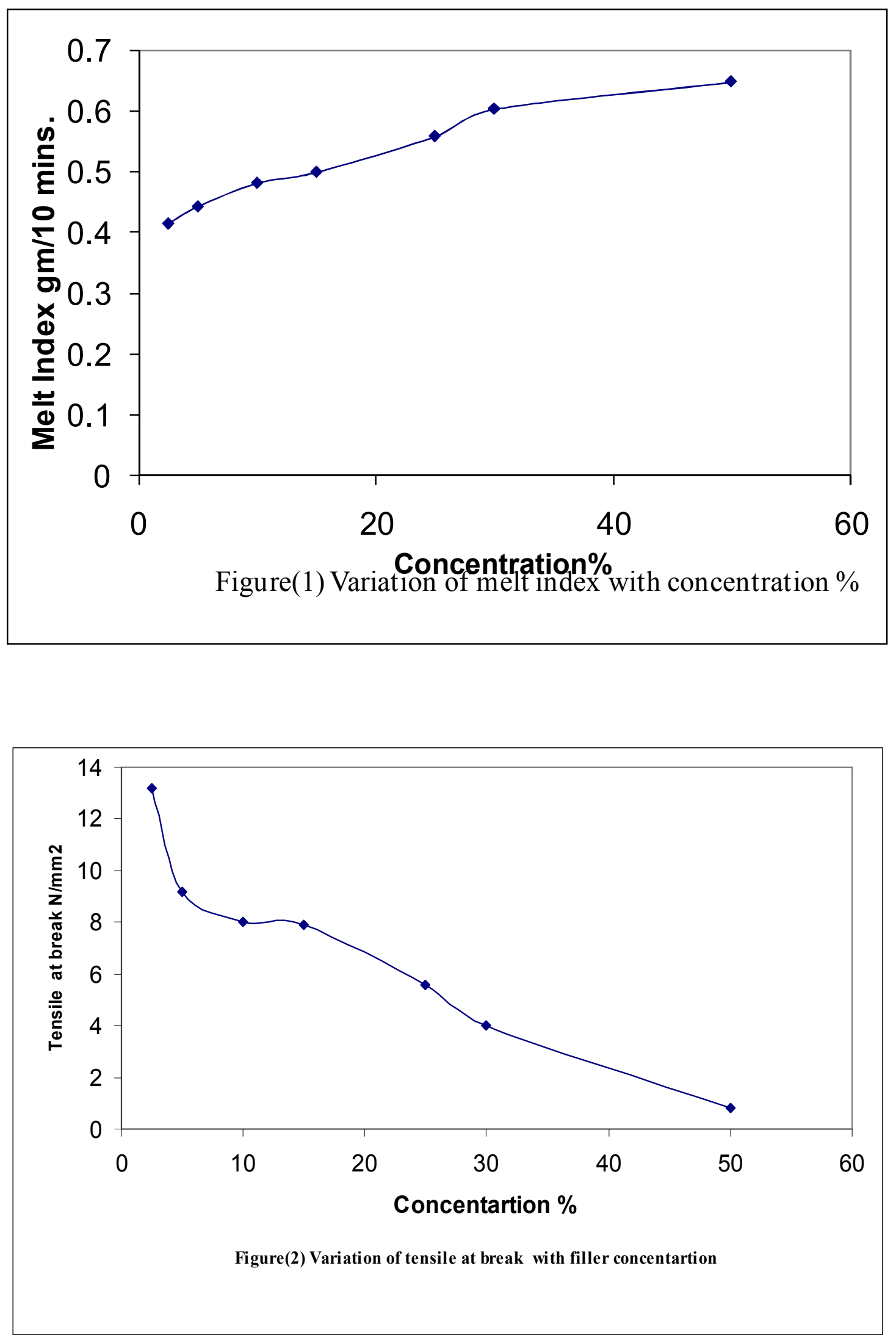
Mechanical Properties of Low Density Polyethylene / Citrus Aurantium Shell ...

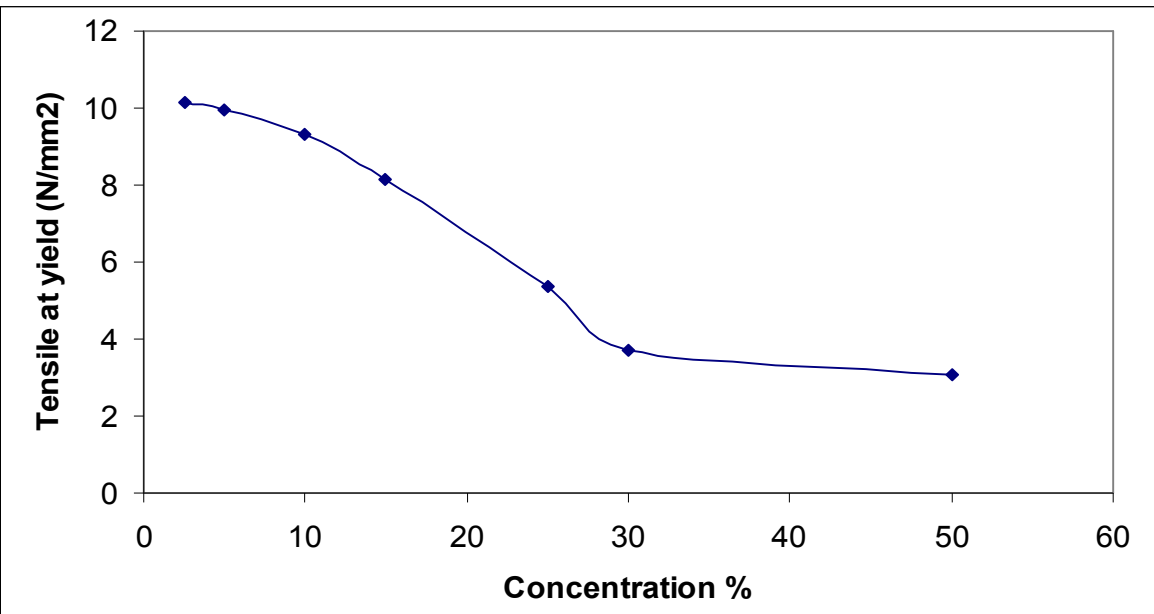

Figure(3) Vaiation of strength at yield with concentration

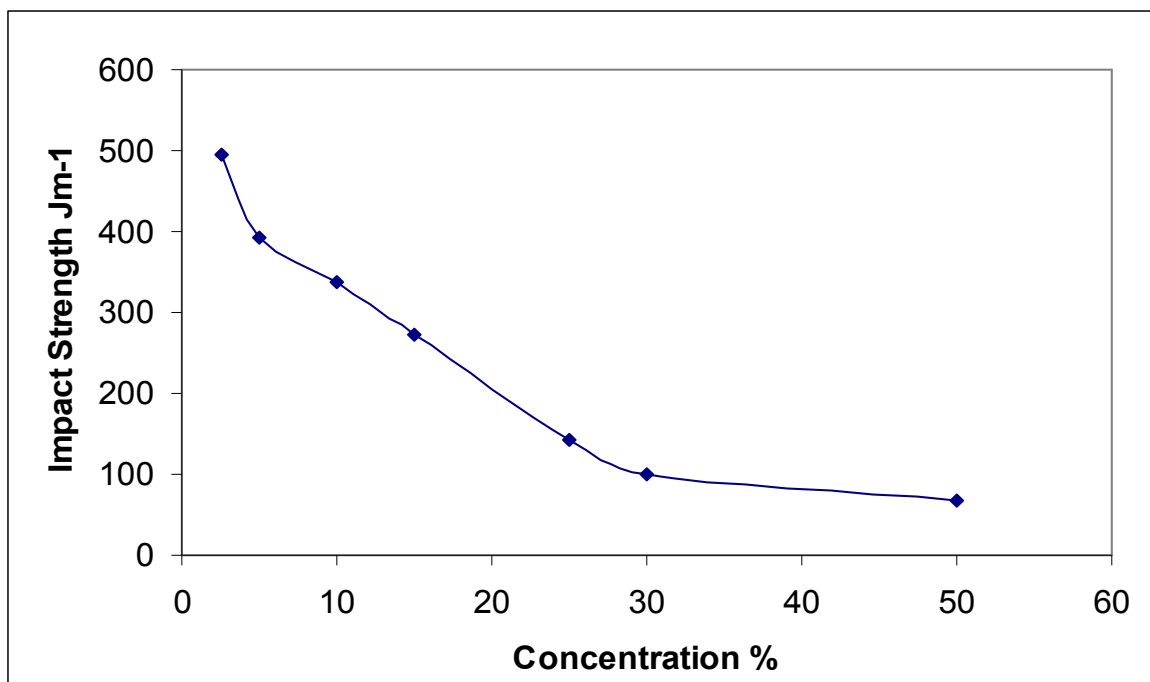

Figure(4) Variation of Impact with concentration

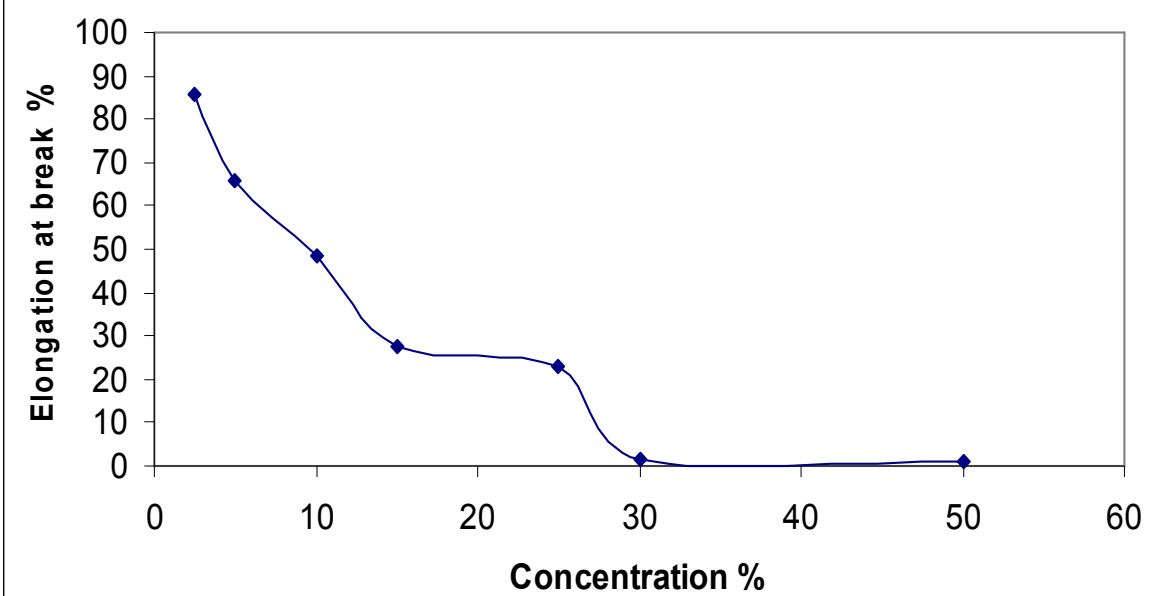

Figure(5) Variation of Elongation with concentration 